\title{
Towards a model of crime variations and solutions: a framework for geographical work
}

\section{Wayne K.D. Davies, Calgary}

\section{Introduction}

Relatively few geographers have contributed to the literature on crime, despite its importance to the urban condition. However, there are some notable exceptions, such as pioneering books (GEORGES-ABEYIE \& HARRIS 1980; HeRberT 1982), or recent research papers and special issues of journals (RACINE 2002, 2004). Most geographers deal primarily with spatial patterns of crime and their association with social or environmental variables. This emphasis is also seen in parallel work by urban ecologists and sociologists, both historically and in contemporary research, such as those that show high correlations between crime and social deprivation (Booth 1894; Sampson \& Groves 1989; Veysey \& MESSNER 1999), or crime and behavioural features, such as social disorganization and anomie (SHaw \& MacKay 1942; Merton 1957; Passas \& Agnew 1997). However, most geographical and ecological work rarely deals with the variety of often competing theories and explanations that account for crime (RECKLESS 1967; Pelfrey 1980; Hagan 1985; Muncie \& McLaughlin 2001; ANDERSON \& DySON 2002). Hence there is a need for some guides to relate the traditional geographical approaches to the wider crime literature, and to summarize the contemporary and multifaceted discourse on crime. Figure 1 attempts this task through a model that shows how studies of crime can be viewed in terms of four different levels of description. This is expressed diagrammatically as a series of concentric rings, each of which contains a series of complementary ideas. In practice, many of these competing ideas are better seen working in conjunction, for crime is such a complex behavioural product that it can only be understood in a multi-causal context. Space constrains mean that this model only provides a summary of the various ways in which crime variations, explanations and solutions can be described, and illustrates how we construct our knowledge of crime.

\section{The construction of crime}

One of the major contemporary changes in social sciences has been the recognition that our knowledge is socially constructed and is based on power relations that lead us to represent objects and activities in particular ways. This owes a great deal to the work of post World War II French linguists and philosophers who have exposed the limitations of the empiricalidealist approaches and questioned the basis of our apparently common-sense understandings of the world (BELSEy 1980). The result, as Foucault (1967) classically showed in relation to mental illness, is that the systems of representation used, especially the classification and pigeonholing of activities and people, have regulated the way we understand, or rather produce meaning. So to simply analyse information presented to us about the numbers and spatial incidence of people with mental illness is no longer enough. These ideas can also be applied to the complex issue of what constitutes crime. Crime is not a simple empirical fact. We construct our knowledge of crime in the sense of how we view, attempt to solve and punish the acts and people that are labelled as criminal. The way we represent crime is conceptualised in the centre of Figure 1 as a scale, divided into pre-crime and postcrime situations, in which the divisions between the various categories vary between societies. The difference between the two begins with what is defined as crime. Superficially, crime is considered to be some type of behaviour that is viewed as abhorrent, or threatening to the norms of society. However, in practice, a crime is not a punishable event unless it has been criminalized, namely publically identified and defined as a crime, so that perpetrators could be punished by the forces of authority in individual political jurisdictions. Major crimes, such as murder, are accepted as being criminal acts by most people, but some societies and groups justify certain murders in terms of their morals, or threats, as in war. But in general, what is criminalized varies between societies and through time, as can be illustrated by current debates about whether homosexuality, abortion and drug use are crimes. So the point at which crime is identified is obviously a relative one; it is one that may be contested by groups, and is often subject to change by new legislation. GotTFREDSON \& HiRSCHI (1990) identified another important aspect of crime, a latent one described as criminality, namely the predisposition to criminal behaviour, rather than the act of a crime itself. But there may be all sorts of other behaviours, especially in cities, where threatening words, actions or anti-social behaviour make others uncomfortable or fearful. They may well be as harmful or unpleasant to others as actual crimes. These anti-social behaviours, or incivilities, may provide a class of actions that lie between the crime act and criminality. Recent British legislation has attempted to reduce the recent increase 


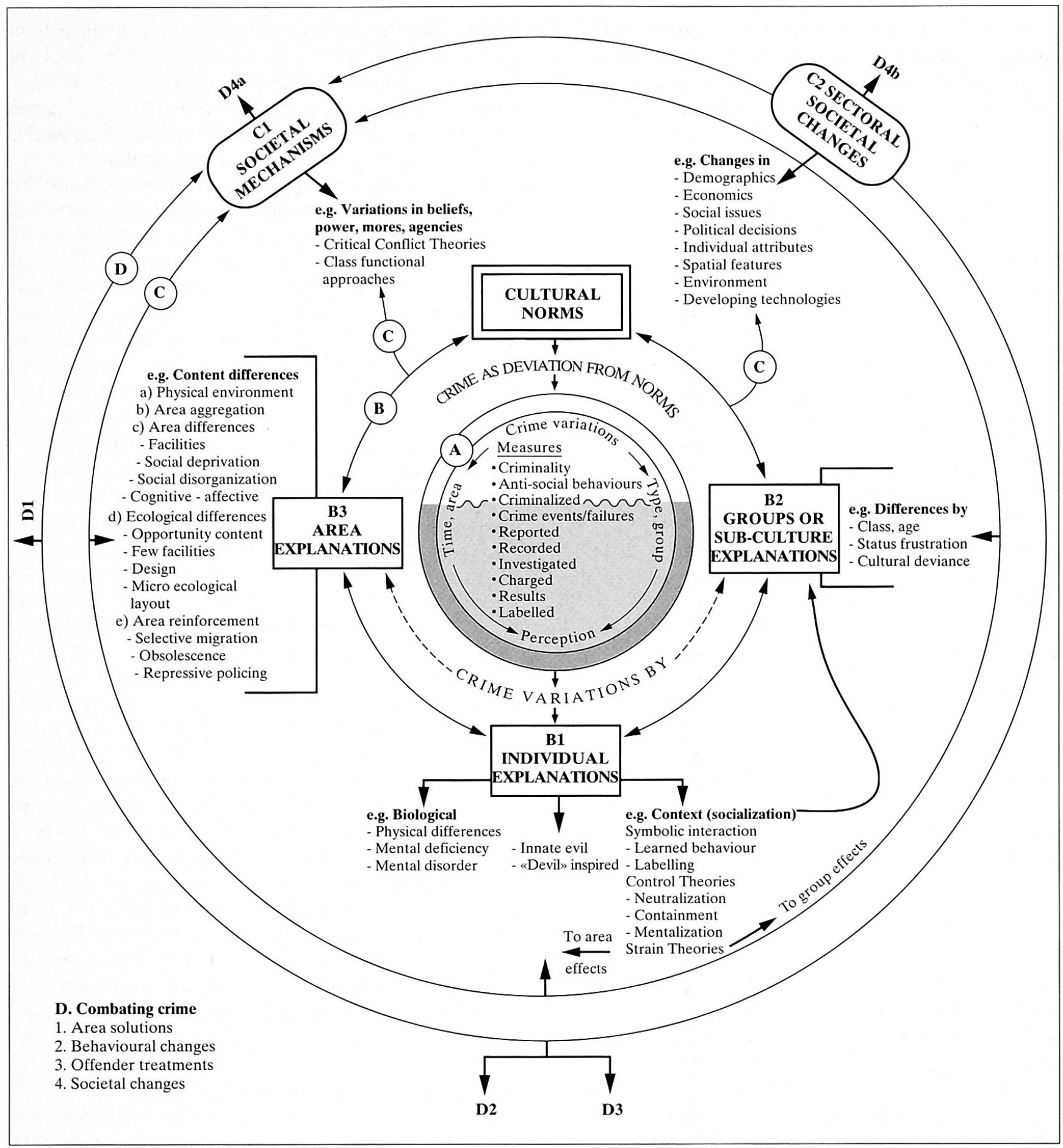

Fig. 1: A model of crime explanations

Unterschiedliche Erklärungsansätze zur Kriminalität im Modell

Un modèle d'approches explicatives de la criminalité

Draft: W.K.D. Davies; cartography: R. PoItras, L. BaumanN 
in anti-social behaviour through a staged approach, the identification of perpetrators, warnings, and finally court appearance and sanctions if the other stages have not stopped the problems (Home OfFICE 2003).

Figure 1 illustrates these differences by showing a porous line as the division between the pre-crime behaviours and the action of crime and its aftermath. But it also shows that the presence of crime, and our knowledge of it, can be conceptualised as follows: from the crime event (or its failure, which may be as important as the act); through the reporting to the police authorities; to being recorded by the police; to being investigated; to suspects being charged; to the results of the judicial system; to the labelling or criminalization of the people convicted, as well as or labelling of areas where there are concentrations of such people (DAVIES 2005). These areas or people may never escape the stigma of being criminalized, which often leads to repeat crime behaviour, or to these persons being ostracized by the population at large. At each of the stages there are the normal errors of measurement and categorization, which means that there may be a big difference between what crime actually occurs, and what society usually expects, namely some form of consequence for the perpetrator. Part of this is due to the efficiency or otherwise of the police and judicial system, whilst it is apparent that at various stages there is a great deal of discretion in what crimes may be recorded or investigated thoroughly. One of the biggest gaps, even in the most effective criminal systems, lies in the difference between the number of crimes that get reported and the number that actually occur. RADZINOWICZ \& KING (1977) estimated that $80 \%$ of crime is unreported, although this varies with crime type.

This summary review illustrates that crime is not the simple empirical fact that is assumed in many studies of the spatial patterns of crime. We socially construct our knowledge within the scale shown in Figure 1, from criminality, or predisposition to crime as a deviant from accepted social norms, to the criminalization of some behaviours through the various levels in Figure 1 , to the conviction and labelling of people as criminals. Hence there can be major gaps between our measurements of crime and the actual crime taking place, and, given the criminality concept, what could have happened. Of course it must also be emphasized that there are variations in the way that different types of crime are dealt with by society and the criminal system, and variations by the extent to which crime is associated with different groups in society, as well as by incidence in area. Moreover, crime incidence varies by time, be this daily or seasonally. PresdeE (2000) has argued, in addition, that in an increasingly organized and rational society many people have a «second life» on weekends or holidays, and some engage in behaviour that is anti-social or even partially criminal as an escape from the constraints of their «normal life». Finally, there is a difference between the actual crime rates, however measured, and what is perceived as the extent of crime by the general population. But the perception is also influenced by different attitudes to crime, for some people do not consider some criminalized behaviours, such as drug use, as being crime. This is especially important in relation to what is often called «white collar» crime, where there are far fewer studies than in the case of crimes against people or property. In addition, there is a difference between the perceptions of perpetrators and victims. Although we tend to view crime negatively, as a deviant behaviour from the social norms of acceptable actions, perpetrators of crime see this quite differently, for their actions may be carried out for pleasure, dominance, or profit. This exemplifies further how the representation and meaning of crime is a social construction. All these issues mean that tracking spatial variations in crime across political areas is a very difficult and contentious task, although there are efforts to introduce comparability in crime surveys from various countries and international agencies (NEWMAN 1999).

\section{Behavioural explanations for crime}

The problems associated with the way that crime is represented can be paralleled by the competing explanations proposed to explain crime. For convenience, they can be grouped into explanations based on individual behaviours, or those linked to groups, or to the effect of areal influences, although the latter are often assumed to be contextual effects and some explanations overlap these groups. Again the choice between these approaches represents a social construction by individuals of what they consider to be the most important.

\subsection{Explanations based on individual deviant behaviour}

The area labelled as B1 in Figure 1 shows examples of the range of explanations proposed to account for the different individual characteristics and behaviours of people who engage in crime. These can be divided into three main groups of explanations, with religious, biological, or social context or socialization factors respectively. The oldest explanations for crime were associated with religious beliefs, based on such ideas as innate evil, or devil-inspired actions. By the late nineteenth century, the focus moved to what are primarily biological explanations. Initially these were based on physical or brain differences, which in turn were superseded by psychological explanations with attention paid to possible mental deficiencies of people who 
commit crime (Pelfrey 1980). Some of these ideas may still be of importance in explaining certain actions classified as crimes, such as those committed by mentally ill people. In the post World War II period more attention has been paid to a third approach, that of criminal character, which is assumed to be the result of socialisation influences. Several different types of explanations have been stressed. One set focuses upon how people get socialized into crime, such as Symbolic Interaction Theories (Blumer 1969), the Differential Association Theory of Sutherland \& CRESSEY (1978), or the «learned behaviour» approach. Other researchers have advocated the Theory of Neutralization (Sutherland 1949; SYKes \& Matza 1957), suggesting that some people are able to neutralize their feelings of guilt or concern over the violation of accepted behaviours by rationalizing that their needs supersede the rights of others, a feature that is shown to be frequently associated with white collar crime

Another set of explanations linked to general socialization factors, take the opposite tack and focus on the constraints that prevent most of us from rebelling against the normal constraints of society. For example, Control Theory (RECKLESS 1967; HIRSCHI 1969) identified the pressures operating on the individual, including those from the surrounding society, that act as restraints on our behaviour. These ideas were extended by GotTFredson \& HiRsCHi (1990) in their General Theory of Crime. This proposed that self-control and crime opportunity are central features of criminal behaviours involving force and fraud, ideas tested by Grasmick et al. (1993) and VAZSONYI et al. (2001). More recently, General Strain Theory (AGNEw 2001) summarized the great range of variables that cause strain or stress on individuals, which increases the likelihood of developing emotions such as anger and frustration. These emotions can produce pressure for corrective action to reduce the strain, which may involve behaviours that breach accepted standards and are considered criminal. The influences incorporated in this theory may also go beyond simple social factors, and include areal and group effects.

An alternative view of socialization has been suggested by FonaGY's (2003) Mentalization Theory, which suggests that violence may be innate and normal. Hence, violence is usually «socialized out» in children through parenting and attachment - rather than being «socialized in» through learning from criminals, which is at the basis of most learned behaviour explanations. He suggests that some people have "no sense of the other", meaning that there is no interest in, or concern for, other people's rights, or privacy. FonAGY argued that the development process of socialization is impeded in some people through a variety of mechanisms, so they have no sense of concern if their victims are vio- lated. Finally, there are other sets of explanations that focus upon addictive behaviours, especially linked to drug use, which is illegal and expensive in most western societies, and which often leads victims to commit crime to «feed their habit».

Although advocates of these various ideas stress the primacy of each preferred approach it must be emphasized that there are many associations between the ideas. The most obvious is that the area characteristics of social deprivation or disorganization are often brought in to help explain the presence of a higher possibility of socialization into crime. Also it is worth noticing how many older ideas have been revitalized and perhaps integrated in rather different ways in recent years. For example, FonAGy's (2003) concept of impaired mentalization in violent people, emphasizes that the "socializing out" of violence in children is, at base, a learned concern that creates respect for the «other» that enables us to live in groups. He also reports recent brain scan research using magnetic resonance imaging (HOFER 2003), which shows how violent people may have deficient brain structure, especially in the prefrontal cortex. However this finding does not lead into a retreat into the older idea of innate or initial brain deficiencies in criminals, as stressed in nineteenth century literature. Rather it may be a difference produced through the absence of positive socialization during the development of the brain as a person grows, especially in the early years that are so influential in affecting the developing physical or cognitive structures. In this context HART \& RISLEY's (2003) comprehensive study of young children shows the vast gulf between the experiences of children from different classes in terms of their exposure to words and also encouragement. These differences must have a huge effect upon language development in the brain and the ability of children to socialize. Those children with little encouragement, support and limited linguistic skills may not be socialized out of innate violence; indeed it is well known that violent behaviour in early childhood often leads to violent behaviour as a teenager (HeRRENKOHL et al. 2001). So it could be argued that the emphasis of many researchers who adhere to theories such as Control or Mentalization Theories is on why people conform, rather than how they deviate. These ideas certainly overlap with Social Control Theories, but reverse the usual connection with violence. In addition, they revive connections with Brain Difference Theories which seek here for explanations for some type of criminal behaviour as opposed to another. Although there have been recent suggestions of a genetic link to serious crime, most recent research stresses the way the socialisation process in early childhood affects the development of the brain. However persuasive these recent ideas may be, there seems little doubt that many of the previous theories or factors of 
explanation have utility in particular cases. Crime in its various manifestations may be the result of so many different factors that it is difficult to ascribe everything to a single theory or set of ideas.

\subsection{Group or sub-cultural effects}

The second set of explanations for crime, summarized in Figure 1 as B2, focus upon the association of crime with particular groups of people, whose distinctive behaviours, or ways-of-life define a particular sub-culture (FISCHER 1976). Some of these behaviours may be defined as deviant by people outside the sub-culture (COHEN 1955), although acceptable to the group, for example a gang (THORnBerRY et al. 1993; ANDERSON 1998). The most prominent of these ideas associate the behaviour with particular characteristics of the sub-group, such as the Class Deviance, Status Frustration and Cultural Deviance Theories (Hagan 1985). At another scale some families have been shown to be sites of violence and cruelty that often goes unrecorded (SARAGA 2001). These sub-group or sub-cultural explanations must be set within the context of the values and moral standards found in other parts of the city, which act as a standard for the conceptualisation of what constitutes crime, as well as its criminalization in law. In the case of class deviance, MILLER (1958) maintained that the way-of-life in working class groups led to a series of potentially criminal behaviours, such as physical aggression, taking matters into ones own hands, inability to control emotions, a drinking culture, or a search for thrills. Such traits are often considered deviant by the middle income and upper income people who controlled, or were influential in setting standards in, society. Yet it is important to note that HAGAN's (1985) review of the literature concluded that there is no evidence of a value difference in the acceptance, or even the tolerance of criminal behaviours by the majority of people in these groups, for the majority of people affected by crime are those who live in the areas with high crime rates, not the people outside. Also, criminologists such as QUINNEY (1977) have argued that these issues need to be looked at in the context of the way that some racial groups and the poor receive discriminatory treatment from the justice system - despite its claims to fairness and equality before the law. The result is an inherent unfairness in the way that crime is constructed, leading to the greater criminalization of certain groups. But it is not enough to simply focus on the internal character of sub-groups. «Status frustration» focuses upon the differences or competitive nature between groups competing for power, resources and status. Since many children from underclass backgrounds cannot meet the standards set by middle class society they reject these values and develop their own, and this may lead to violence (HEIMER 1997). This rebellion against the mores of the host society also may be one way of achieving recognition and preserving self-esteem. The third example, or «cultural deviance» approach stresses the fact that many individual cultural groups have different attitudes to what constitutes a crime (SAmpson \& Wilson 1995). Perhaps the classic case may be attitudes among members of some street gangs (ANDERSON 1998) who may not see petty theft as anything more than taking from the «richer people».

The value of this «cultural deviance» approach in explaining crime variations may be most obvious when groups who have different attitudes from the host society regarding drugs, private possessions and violence, are concentrated in ethnic intra-urban areas, and their behaviour is defined and charged as criminal. Such issues can be extended to deal with age group deviance where young adults, and males in particular, may try to adopt adult behaviour, such as drinking, smoking, driving cars, that is still legally forbidden. Such groups may simply be anticipating their maturity when such actions are not criminalized, or engage in illegal behaviours, to test or challenge the rules of society in which they have been brought up. Others are seeking excitement and perhaps status among their peers by deliberately flouting these rules, especially through burglary or stealing cars, since this provides the thrills and risks of life that are otherwise missing.

\subsection{Area effects}

The third approach to explanation is another aggregation issue, this time with the characteristics of areas (B3 in Figure 1) where crime occurs, rather than with groups of people. It is an explanation often favoured by ecologists and geographers, but has usually been considered more of a contextual explanation or an association, rather than a direct causal effect, by most criminologists. One spatial effect is the way that the spatial or areal aggregation of people is assumed to lead to behavioural strains and increasing incidence of crime. The oldest explanations are those that tie the size and growth of cities with increasing crime levels (Wirth 1938; Graham \& Clarke 2001). In addition, it could be argued that aspects of the physical environment, especially climate, may play a contributing role in some crime variations, or rather may help to trigger them, although it is important to be careful of not falling into the determinist trap. More specific causal explanations are linked to the way that people with certain social traits are concentrated in specific areas, since they produce intra-urban areas with specific characteristics that either account for, or increase the propensity to crime. The best known of these is the well known concept of social deprivation (BоoTH 1894; Shaw \& MacKay 1942; SutTles 1968), where crime-ridden inner city areas are usually measured by such indicators as low socio-economic status, high unemployment or people on welfare, high mobility, 
and family breakdown, with lots of single parent families or people living alone, and sometimes high ethnicity. All, or some of these variables often seem to characterize high crime areas, and may be given causal status rather than just casual associations. A more behavioural focus can be seen in the use of terms such as social disorganization and anomie (PASSAS \& AGNEW 1997) to characterize many areas. This is based on the idea that the absence of local ties to family or neighbours, as well as role models to condemn antisocial behaviour, lead to a breakdown in the «normal» social connections. In essence they reduce the element of control, or influence, that socializes people into what the host society sees as acceptable behaviours, and through the presence of criminals and limited policing, provide a breeding ground for people to engage in anti-social and perhaps criminal behaviour. Clearly these ideas can be linked to the various Control Theories outlined above. Far less attention has been paid to another domain of variables associated with particular crime areas, namely the attitudes and feelings of people in crime areas, which may create or at least encourage anti-social behaviours, as suggested by RACINE (2002). DAVIES (2004) has recently proposed a set of ten dimensions of variation in the affective domain, which are seen as leading to «terrains» of distinctive character in crime areas, although it is suggested that these are really special cases of more general sets of community area differentiation that have been proposed and measured (Davies \& Herbert 1993; Davies \& Townshend 1999).

Another set of spatial or ecological explanations for crime are linked to a series of contextual spatial or ecological effects. One relates to the opportunity content of the area: the extent to which facilities in an area provide opportunities for crime without retribution, such as the absence of people, presence of late night shops, people perceived as potential victims. Other scholars point to the absence of area facilities in crime areas, such as youth clubs or sports facilities. The argument here is that such facilities may deflect aggressive behaviour into other pursuits, thereby reducing the number of idle youth who may turn to crime (LaGrange 1999). Newman's (1972) «defensible space» concept focuses upon another spatial issue: the design of areas. He showed that the number of escape routes, the extent of surveillance, as well as anonymity, were important components in accounting for high crime rates in high-rise public housing estates, an issue also explored by COLEMAN (1985). More recently, TAYLOR (1997) has shown how street blocks encourage interaction and thereby reduce crime levels. A related set of ideas relate to the presence of micro-ecological features, which may provide those who have a high propensity to crime an opportunity to pinpoint particular locations to burgle, such as easy access base- ments, the absence of secure locks on doors, screened entrances, the absence of lights, or even few people on the street at night. Although these features may show strong correlations with areas with higher crime rates, most researchers see these area issues as contextual effects that may help in reducing or encouraging crime, rather than being causal in origin.

Finally, a series of area reinforcement effects seem to affect crime rates. One important issue is selective migration from crime areas, in which the economically advantaged and the role models leave, and are replaced by populations less skilled, less socially connected, as well as those with a drug habit or mental illness, which may make them more crime prone. The second is the increasing obsolescence of many buildings, which may encourage some individuals to vandalize property that seems to have little value or protection, which increases the dilapidation of areas. Third, repressive policing may alienate a local population, and make them less likely to co-operate with the forces of law and order. The combination and progressive incidence of these and related features may quickly transform an area from one with low to high crime rates.

\section{Societal causes for crime}

Figure 1 shows that the third major set of explanations for crime are located in the overarching societal conditions of society. In these approaches deviant behaviour is not seen as something that is an unfortunate social blemish, inflicted by certain individuals or groups on an otherwise peaceful and consensual society. Instead, crime is seen as a consequence of certain societal conditions, be these either the superstructures or mechanisms of societies, or emerging sectoral changes within a society.

\subsection{Structuralist approaches}

The first of these societal explanations are often called Critical Conflict Theories because they attribute crime to the deep-seated structures or mechanisms of society that create conditions in which crime can emerge. Obviously there are many varieties of the general societal types, whether feudal, capitalist, command or other structures, which have different relationships to the behaviours seen as criminal. But the most plausible crime association comes from the Marxist view of capitalist societies, which is seen to possess many features that lead to the root of numerous crimes, namely: the basic inequality of rewards to different classes of people. Examples of such features would be: the dominance of the capital-owning class, and their ability to frame laws in society that protect their property and interests; or the commodification of most goods and 
services rather than provision by reciprocal or other relationships, which puts many desired goods beyond the reach of many people; or economic booms and slumps that lead to conditions of periodic impoverishment. These conditions led MarX and others to argue that the wage labour class are alienated because they lack the means to share in the rewards of capitalist society, so some turn to crime as a way-of-life. Indeed, it has often been argued that one of the problems in western society is that avenues of progression to the legitimate rewards of society, such as a good job, money and possessions, are unobtainable by uneducated youths of slum areas, so «normal channels of progression» are blocked. Hence some turn to criminal means to obtain these rewards. Although MarX did not really apply his ideas to crime in any detail, Marxist-influenced criminologists and sociologists from the late 1960s (Turk 1969; QuinNEy 1977) used these ideas in a ferocious attack upon the typical mid-century emphasis upon the social character or psychology of individuals as explanations for crime.

Not all societal theorists agreed with the dominance of economic materialist ideas. After all, relatively few poor working class people actually turn to crime, as one might be led to expect from a simple application of Marxist ideas, although Marxists argue that they may be hoodwinked through social conditioning into supporting the anti-crime attitude of other classes. More general criticisms come from those who emphasized that society is an amalgam of consensual and conflict tendencies (DAHRENDORF 1959; TURK 1969). These researchers argue that it is not simply different classes, but individuals and groups that compete for power and authority to establish control over others and access to resources. Some subordinate members may resent their lack of resources and influence, reject the existing social constraints to obtain resources, and turn to what the host society views as crime. Although the mechanisms of these and other alternative structuralist ideas vary, advocates of these views are alike in placing the propensity to commit crime upon the character of societal factors. Yet others are more cautious in suggesting that crime will only occur if there are also individual behavioural, subculture norms or area factors at work, which provide the trigger to engage in crime.

\subsection{Recent societal changes}

It must also be remembered that society is never static. A large number of recent individual changes in various sectors of contemporary societies may increase or decrease the propensity of particular people, groups, or inhabitants in certain areas to high or low crime rates because of the way these changes cause disruptions in existing societal, economic or moral conditions. In the last thirty years a variety of new influences have created new pressures that has lead to increasing crime rates, especially in obsolescent inner cities that lost their own blue-collar jobs, or in many high rise public housing estates that have turned into slums or dilapidated areas. Space constraints mean that it is impossible here to provide a complete overview, although a summary framework, with examples, for studying these changes is provided in Table 1.

It is the cumulative effect of these changes in western societies that has undoubtedly led to an increase in the fear and experience of crime in many areas.

\section{Combating crime}

The problem of crime has led to an enormous number of methods to combat its rise and to reduce its impact, especially in areas of high crime rates. Figure 1 shows that these can be summarized in terms of four very different approaches, each of which may be linked to various explanations for crime that are explained in more detail elsewhere (DaVIEs 2005). One approach is to create area change (D1), to change one or more of the characteristics of the area that seem to be correlated with crime, for example by reducing social deprivation, changing attitudes, or reducing the opportunity for crime. An alternative approach would be to change individuals with crime propensity before crime occurs by influencing, for example, specific individual or group behavioural (D2) characteristics (see Figure 1 , second concentric ring). Another individual behaviour approach is to focus on actions taken once the offender is found guilty, by focusing upon offender treatment (D3), e.g. from warnings, to fines, or incarceration, and by designing policies to reduce the possibility of offenders committing crimes in the future. A more fundamental approach would be to try and change the structure of society, for example, by reducing inequalities and exclusion of people by equalizing access to the system of rewards and power within society (D4), or in a more short term sense by immediately counteracting smaller changes in any sector of society that appear to be leading to higher levels of crime. Relatively few geographers have explored the differential spatial variations in these alternative ways of trying to control crime, although in practice, elements of all approaches are usually used.

\section{Conclusions}

This article has outlined a summary model of crime variations and solutions in order to show how geographers can relate their studies to the wider criminology literature. It has been shown that crime is not an easy problem to define. At each stage in our under- 
Demographic-ethnic, e.g. more independence and less supervision of youths; more young males, which often leads to higher crime levels; tensions from the incidence and migration of different cultural groups.

Economic, e.g. fewer low skill occupations and greater need of high skill labour in new economy, leading to greater inequality and strains in society, which may lead some to crime.

Social, e.g. declining family links and religious beliefs, providing less moral instruction; women having less time in the home, resulting in less surveillance or monitoring of children; less social capital, providing fewer alternative outlets or guidance for youth.

Political, e.g. less interest in equality, so less effort to alleviate poverty-problem areas; release of the mentally ill into community; increase in incarceration, breeding resentment and labelling of people as criminal.

Individual behaviour, e.g. many of the old constraints on violent behaviour have broken down in society; less deference to authority, lower inhibitions; more violence «without content».

Spatial or territorial differences, e.g. high availability and use of knives, guns and drugs in some areas; high levels of police repression in some regions.

Environmental, e.g. poor design and quality in public housing estates; lower defensible space.

Development of new technologies, e.g. greater mobility, which increases the range of criminal opportunity and escape; greater awareness of inequalities, through films and television, creating unrealistic expectations, as well as more exposure to the incidence of crime, leading to an increased perception of fear.

Table 1: Recent societal changes

Aktuelle Gesellschaftsveränderungen

Changements sociaux récents

standing we need to recognize that our knowledge of crime incidence, the way we represent it, as well as the issues different people focus on, has been constructed by various decisions, rather than being simple empirical facts. So like most knowledge and understandings, it is based on our values, our choices and especially the power structures that condition how we view the behaviours that are labelled as criminal. In other words, the way we represent and study crime involves socially constructed preferences. It is to be hoped that by showing how traditional geographical work relates to a wider body of literature on crime and the way we construct our knowledge, will lead to more general explanations of one of our biggest urban problems.

\section{References}

Agnew, R.A. (2001): Building on the foundation of general strain theory: specifying the types of strain most likely to lead to crime and delinquency. - In: Journal of research in crime and delinquency 38,4 : 319-361.

ANDERSON, E. (1998): The social ecology of youth violence. - In: Crime and justice: a review of research 24: 65-104.
Anderson, J.E. \& L. Dyson (2002): Criminological theories. - Lanham, Maryland, U.S.A.: University Press of America.

BELSEY, C. (1980): Critical practice. - London: Routledge. Blumer, H. (1969): Symbolic interactionism. - Englewood Cliffs, New Jersey: Prentice Hall.

Bоотн, C. (1894): Life and labour of the people of London. - In: Journal of the Royal Statistical Society 55: 557-591.

CoHen, A.K. (1955): Delinquent boys: the culture of the gang. - New York: Free Press.

Coleman, A. (1985): Utopia on trial. - London: Hilary Shipman.

DAHRENDORF, R. (1959): Class and conflict in industrial society. - Stanford: Stanford University Press.

DAVIES, W.K.D. (2004): Affective dimensions of urban crime areas: towards the psycho-geography of urban problem areas. - In: Geographica Helvetica 59, 3: 218-226.

Davies, W.K.D. (2005): The social construction of crime variations. - In: MuriYAMA, Y. (ed.): Monitoring cities. - Proceedings of the IGU Urban Commission, Tokyo: 232-243.

Davies, W.K.D. \& D.T. Herbert (1993): Communities within cities: an urban social geography. - London: Belhaven Press, New York: Halsted Press. 
Davies, W.K.D. \& I.J. Townshend (1999): Identifying the elements of community character. - In: Research in community sociology 9:219-251.

FisCHER, C.S. (1976): Toward a subcultural theory of urbanism. - In: American journal of sociology 80: 1319-1340.

FonAGy, P. (2003): Towards a developmental understanding of violence. - In: British journal of psychiatry 183: $190-192$.

Foucault, M. (1967): Madness and civilization. London: Tavistock-Routledge.

GeORGES-ABEYIE, D.E. \& K.D. HARRIS (1980): Crime: a spatial perspective. - New York: Columbia University Press.

GotTFRedson, M.R. \& T. HiRsChi (1990): A general theory of crime. - Stanford: Stanford University Press.

Graham, P. \& J. Clarke (2001): Dangerous places: crime and the city. - In: Muncie, J. \& E. McLaughlin (eds): The problem of crime. $-2^{\text {nd }}$ edition, London: Sage Publications: 152-189.

Grasmick, H.G., Trtrle, C.R., Bursik, R.J. \& B.J. ArNeKlev (1993): Testing the core empirical implications of Gottfredson and Hirschi's general theory of crime. - In: Journal of research in crime and delinquency 30, 1: 7-29.

HaGaN, J. (1985): Crime, criminal behaviour and its control. - New York: McGraw-Hill.

HART, B. \& T.R. RisLEY (2003): Meaningful differences in the everyday life of young American children. New York: Brookes Publishing

HeImer, K. (1997): Socio-economic status, sub-cultural definitions and violent delinquency. - In: Social forces 75: 799-833.

HERBERT, D.T. (1982): The geography of urban crime. London: Longman.

Herrenkohl, T.I., Huang, B., Kosterman, R., HawKins, J.D., Catalano, R.E. \& B.H. Smith (2001): A comparison of social development processes leading to violent behaviour in late adolescence for childhood initiators and adolescent initiators of violence. - In: Journal of research in crime and delinquency 38,1 : 45-63.

HirSCHI, T. (1969): Causes of delinquency. - Berkeley: University of California Press.

Hofer, M.A. (2003): The emerging neurobiology of attachment and separation: how parents shape their infants brain and behaviour. - In: COATES, S.W., Rosenthal, J.L. \& D.S. Schechter (eds): September 11: trauma and human bonds. - Hillsdale, New Jersey: Analytic Press: 191-209.

Home Office (United Kingdom) (2003): Respect and responsibility: taking a stand against anti-social behaviour. - London: U.K. Stationary Office, CM 5778.

LaGrange, T.C. (1999): The impact of neighborhoods, schools and malls on the spatial distribution of property damage. - In: Journal of research in crime and delinquency $36,4: 393-422$.
Merton, R.K. (1957): Social theory and social structure. - Glencoe, Illinois: Free Press.

MiLleR, W. (1958): Lower class culture as a generating milieu of gang delinquency. - In: Journal of social issues 14: 5-19.

Muncie, J. \& E. McLaughlin (2001): The problem of crime. $-2^{\text {nd }}$ edition, London: Sage Publications.

Newman, O. (1972): Defensible space. - New York: Macmillan.

Newman, G. (ed.) (1999): Global report on crime and justice. - New York: United Nations Office for Drug Control and Crime Prevention, Oxford: Oxford University Press

Passas, N. \& R. Agnew (1997): The future of anomie theory. - Boston: North Eastern University Press.

Pelfrey, W.V. (1980): The evolution of criminology. Cincinnati: Anderson Publishing.

Presdee, M. (2000): Cultural criminology and the carnival of crime. - London: Routledge.

Quinney, R. (1977): Class, state and crime. - New York: David MacKay.

RACINE, J.-B. (2002): Explaining, regulating or monitoring violence in the cities of tomorrow: appraisals from French and Swiss experience. - In: DaviES, W.K.D. \& I.J. TownSHEND (eds): Monitoring cities: international perspectives. - Calgary: International Geographical Union, Urban Commission: 557-597.

RACINE, J.B. (2004): Urban violence: a challenge for geographers? - In: Geographica Helvetica 59, 3: 178-181.

Radzinowicz, I. \& J. KING (1977): The growth of crime. - London: Hamish Hamilton.

ReCKLESS, W.C. (1967): The crime problem. $-4^{\text {th }}$ edition, New York: Appleton-Century-Crofts.

Sampson, R.J. \& W.B. Groves (1989): Community structure and crime: testing social disorganization theory. In: American journal of sociology 94: 774-802.

SAMPSON, R.J. \& W.J. Wilson (1995): Toward a theory of race, crime and urban inequality. - In: HAGEN, J. \& R. Peterson (eds): Crime and inequality. - Stanford: Stanford University Press: $37-54$.

Saraga, E. (2001): Dangerous places: the family as a site of crime. - In: Muncie, J. \& E. McLaughlin (eds): The problem of crime. $-2^{\text {nd }}$ edition, London: Sage Publications: 192-234.

SHAw, C.R. \& H.D. MacKaY (1942): Juvenile delinquency and urban areas. - Chicago, Illinois: University of Chicago Press.

Sutherland, E.H. (1949): White collar crime. - New York: Dryden Press.

Sutherland, E.H. \& D. Cressey (1978): Principles of criminology. $-7^{\text {th }}$ edition, Philadelphia: Lippincott.

Suttles, G. (1968): The social order of the slum. - Chicago: University of Chicago Press.

SYKES, G. \& D. MATZA (1957): Techniques of neutralization: a theory of delinquency. - In: American sociological review 22: 664-670. 
TAYLOR, R.B. (1997): Social order and disorder of street blocks and neighborhoods: ecology, microecology and the systemic model of social disorganisation. - In: Journal of research in crime and delinquency 34,1 : 113-155.

Thornberry, T.P., Krohn, M.D., LizotTe, A.J. \& D. ChARD-Wierschem (1993): The role of juvenile gangs in facilitating delinquent behaviour. - In: Journal of research in crime and delinquency 30, 1: 55-87.

TURK, A.T. (1969): Criminality and the legal order. Chicago: Rand McNally.

Vazsonyi, A.T., Pickering, L.E., Junger, M. \& D. Hessing (2001): An empirical test of a general theory of crime: a four nation comparative study of self-control and the prediction of deviance. - In: Journal of research in crime and delinquency 38, 2: 91-131.

VEYSEY, B.M. \& S.F. MESSNER (1999): Further testing of social disorganization theory: an elaboration of Sampson and Groves's community structure and crime. In: Journal of research in crime and delinquency 36,2 : 156-174.

WIRTH, L. (1938): Urbanism as a way of life. - In:American journal of sociology 64: 1-24.

\section{Abstract: Towards a model of crime variations and solutions: a framework for geographical work}

A model of alternative approaches to the study of crime provides a framework for future geographical work, incorporating key components of the criminology literature as well as spatial issues. It is shown how the phenomena of crime, and anti-social behaviour in general, is a "social construction», illustrating the relativist nature of the way we represent. The model also shows that explanations for crime variations can be summarized in terms of two broad approaches: either individual behaviour, sub-group or area effects, or from societal mechanisms.

\section{Zusammenfassung: Annäherung an ein Modell der} Kriminalitätsvariationen und -lösungen: ein Rahmen für geographisches Arbeiten

Ein Modell alternativer Erklärungsansätze zur Kriminalität bietet einen Rahmen für die zukünftige geographische Forschung. Darin enthalten sind Schlüsselkomponenten aus der wissenschaftlichen Literatur zur Kriminalität ebenso wie räumliche Sachverhalte. Der Artikel zeigt auf, dass kriminelle Phänomene und asoziales Verhalten im allgemeinen eine soziale Konstruk- tion und daher relativistischer Natur sind. Das Modell zeigt zudem auf, dass es zwei grosse Erklärungsansätze zur Kriminalität gibt: einerseits auf der Ebene des individuellen Verhaltens, der Subkultur oder der lokalisierten Nachbarschaftseffekte, andererseits als gesamtgesellschaftlichen Prozess.

Résumé: Un modèle des variations de la criminalité et des solutions à y apporter: une perspective géographique

La criminalité urbaine peut être abordée, en matière de recherche géographique, par un modèle alternatif. Celui-ci comporte d'une part des éléments théoriques portant sur la criminalité issus de la littérature scientifique et d'autre part des considérations plus spécifiquement spatiales. Il permet de montrer que la criminalité et les comportements anti-sociaux doivent être considérés comme des constructions sociales et, consécutivement, sont de nature relativiste. Le modèle montre en outre que les explications fournies en matière de criminalité peuvent être divisées en deux approches principales: d'une part celles qui s'appuient sur le comportement individuel, les sous-groupes qui forment la société et les effets de proximité; d'autre part celles qui s'appuient sur des processus sociaux globaux

Prof. Dr. Wayne K.D. Davies, Department of Geography, University of Calgary, 2500 University Drive, Calgary, Alberta, Canada, T2N $1 \mathrm{~N} 4$.

e-mail:wdavies@ucalgary.ca

Manuskripteingang/received/manuscrit entré le 5.7.2005

Annahme zum Druck/accepted for publication/accepté pour l'impression: 16.12.2005 